\title{
Paternally inherited deletion of CSH1 in a patient with Silver-Russell syndrome
}

Thomas Eggermann, Katja Eggermann, Susanne Mergenthaler, Ruprecht Kuner, Peter Kaiser, Michael B Ranke, Hartmut A Wollmann

\begin{abstract}
In a continuing study on the aetiology of Silver-Russell syndrome (SRS), we detected a patient with a heterozygous deletion in the growth hormone gene cluster (17q22-q24). The deletion of the chorionic somatomammotrophin hormone 1 (CSH1) gene was inherited from the patient's father. The patient shows typical symptoms of SRS. Though deletions of CSH1 have been reported without any phenotypic consequences, the heterozygous deletion might be involved in the aetiology of SRS in the case presented here. Apart from other observations in SRS, like maternal uniparental disomy 7 , changes in the genomic region 17q22-qter might be responsible for the expression of this syndrome for at least some of the patients, leading to the heterogeneity of SRS.

( $($ Med Genet 1998;35:784-786)
\end{abstract}

Keywords: Silver-Russell syndrome; chorionic somatomammotrophin hormone 1 (CSH1); growth hormone gene cluster

Silver-Russell syndrome (SRS), a malformation syndrome characterised by pre- and postnatal growth retardation, has been described in more than 380 patients, most of them being sporadic cases. ${ }^{1}$ The aetiology is not yet known. Even though a few patients with chromosomal abnormalities have been described, there is no uniform pattern of genetic abnormalities, apart from two SRS patients where the chromosomal region 17q25 was involved in chromosomal rearrangements. ${ }^{23}$ Additionally, several patients with features similar to SRS and partial monosomy for distal $15 \mathrm{q}$ have been reported. ${ }^{4}$ Studies published previously describe maternal uniparental disomy for the entire chromosome 7 in almost $10 \%$ of the patients..$^{5-8}$

The human growth hormone $(\mathrm{GH})$ gene cluster is localised in the vicinity of the breakpoint 17q25 (17q22-q24). It consists of two $\mathrm{GH}$ genes and three genes encoding chorionic somatomammotrophin hormones $(\mathrm{CSH})$, the arrangement of which in the GH gene cluster has been defined as $5^{\prime} \mathrm{GH}-\mathrm{N}$ (normal) CSH-L (like) - CSH1 - GH-V (variant) CSH2. ${ }^{\circ}$ Only GH-N, CSH1, and CSH2 are thought to be expressed. CSHs are expressed by the placental syncytiotrophoblast and therefore their genetic determination is a function of the fetal genome. For the two functional chorionic CSHs, a gene dosage effect in the case of deletions of one of the genes has been described, a situation somewhat comparable to that in the $\alpha$ thalassaemias. ${ }^{10}$

To evaluate the number of SRS patients with genomic variations in the GH cluster, we screened 54 SRS families with a short tandem repeat marker (STR) located in this cluster. Further characterisation of the $\mathrm{GH}$ gene cluster was performed with a specific cDNA probe.

\section{Case report}

The patient was born at 30 weeks of gestation by caesarean section. Severe growth retardation was detected in the 23 rd week by ultrasound. The operation was performed because of oligohydramnios and an acute deterioration of CTG. At birth, the infant had symmetrical growth retardation with a weight of $640 \mathrm{~g}\left(-3.9 \mathrm{SD}^{11}\right)$, a length of $32.5 \mathrm{~cm}(-3.4$ SD), and a head circumference of $22.7 \mathrm{~cm}$. The placenta was small with infarctions. The patient was the second child of a healthy mother. The first child was born prematurely after 28 weeks and died 10 days postnatally. The mother's height is within the normal range $(161 \mathrm{~cm},-0.6 \mathrm{SD})$, whereas the father is short $(163 \mathrm{~cm},-2.2 \mathrm{SD})$. The patient's motor development was slightly delayed and in childhood he had behavioural difficulties with hyperactivity. Myopia was diagnosed at the age of $2 \frac{1}{2}$ years and is not progressive. In infancy, the patient exhibited typical dysmorphic features of SRS with a large forehead and a small, asymmetrical face. Throughout infancy and childhood, severe growth failure continued. At the age of $71 / 2$ years he had a height of 108.9 $\mathrm{cm}(-3.1 \mathrm{SD})$ and a weight of $14.7 \mathrm{~kg}(-2.8$ $\mathrm{SD}$ ); bone age was $5 \frac{1 / 2}{2}$ years (Greulich and Pyle). Studies performed at this age showed a normal male karyotype, normal GH secretion, and normal values for serum IGF-I, IGFBP-3, and thyroid hormones.

\section{DNA studies}

Genomic DNA was extracted from peripheral lymphocytes of the patient and his parents according to standard protocols. ${ }^{13} \mathrm{~A}$ cell line is not available.

To identify variations in the GH gene cluster, short tandem repeat typing (STR) of the D17S254 locus ${ }^{14}$ was carried out. D17S254 is localised in the $\mathrm{GH}$ cluster, $1.4 \mathrm{~kb}$ upstream of $\mathrm{CSH} 1$ and $11.6 \mathrm{~kb}$ downstream of CSH-L. Additionally, we typed the following STRs to confirm biparental origin of the chromosomes 17: (17pter)-D17S1866-D17S926-D17S1606D17S254-D17S948-D17S802-(17qter) (table 1). Data and PCR conditions can be obtained 
Table 1 Results of STR typing in the patient heterozygous for the CSH1 deletion and his parents. The order of the loci corresponds to the map published by Dib et al ${ }^{33}$

\begin{tabular}{lllll}
\hline Locus & $\begin{array}{l}\text { Allelic status } \\
\text { of father }\end{array}$ & Mother & Patient & Informativity* \\
\hline D17S1866 & $3-4$ & $1-2$ & $1-4$ & Biparental \\
D17S926 & $1-1$ & $1-2$ & $1-1$ & Heterozygosity \\
D17S1606 & $1-3$ & $1-2$ & $1-3$ & Hemizygosity \\
D17S254 & $1 \dagger$ & $2-3$ & 3 & Heterozygosity \\
D17S948 & $2-3$ & $1-3$ & $1-3$ & Biparental \\
D17S802 & $1-2$ & $3-4$ & $2-4$ & \\
\hline
\end{tabular}

^Informativity in respect to the patient's allelic status.

tThe father's monoallelic status in D17S254 might be interpreted as hemizygosity.

from the Genome Database. To exclude the possibility of allelic non-amplification ${ }^{15}$ of D17S254, we designed a new pair of primers spanning the polymorphic region. Primer sequences can be requested from the authors. STR PCR products were analysed by sequencing gel electrophoresis and bands were visualised by silver staining.

For further analysis of the observed hemizygosity in the $\mathrm{GH}$ gene cluster in one of our patients, we used the GH cDNA cGH800 probe. ${ }^{16}$ The probe contains nearly the full length cDNA of the human growth hormone and is homologous to the five genes in the $\mathrm{GH}$ cluster. Four $\mu \mathrm{g}$ of genomic DNA of the patient and his parents as well as of healthy controls was digested with restriction endonucleases $B a m H I$ or HindIII at $4 \mathrm{U} / \mu \mathrm{g}$ DNA for six hours. Digested DNA was subjected to electrophoresis on a $0.7 \%$ agarose gel. Transfer to Hybond $\mathrm{N}^{+}$nylon membranes (Amersham) was performed by alkaline blotting and $25 \mathrm{ng}$ of the non-linearised cGH800/pSPT 18 plasmid was labelled with ${ }^{32} \mathrm{P}-\mathrm{dCTP}$ using a random priming DNA labelling kit (Amersham). Hybridisation was performed at $42^{\circ} \mathrm{C}$ overnight. After stringent washing at $60^{\circ} \mathrm{C}$, filters were autoradiographed overnight with $x$ ray film at $-70^{\circ} \mathrm{C}$.

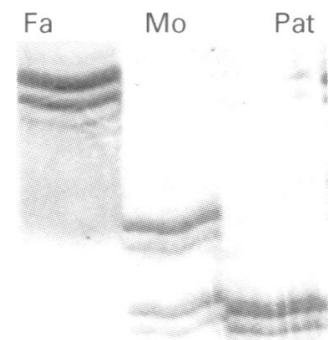

\footnotetext{
$1 \quad 2-3 \quad 3$

Figure 1 Typing of the STR D17S254 shows hemizygosity of the patient. The patient has inherited only one maternal allele (3) and no paternal allele was detectable. The father's "homozygosity" at this locus (allele 1) corresponds to the hemizygosity at this locus observed by using a $G H-c D N A$ probe. The slight band shift between the maternal and patient's PCR product is an artefact. $\mathrm{Fa}=$ father, $\mathrm{Mo}=$ mother Pat $=$ patient.
}

\section{Results and discussion}

In this study we screened SRS patients for genomic variations in the $\mathrm{GH}$ cluster (17q23$24)$. By typing 54 SRS families with the STR D17S254, we observed hemizygosity in one out of 46 informative cases. Analysis of the patient's DNA showed only one maternal allele (fig 1) but no paternal allele. Allelic nonamplification, as described by Koorey et al, ${ }^{15}$ could be excluded. Biparental inheritance of the homologous chromosomes 17 was shown by analysing further STRs on chromosome 17 (table 1). Paternity was assessed by typing five STRs from chromosomes other than chromosome 17.

To identify a possible deletion in the $\mathrm{GH}$ gene cluster of the hemizygous patient, we hybridised the DNA of the patient and parents as well as that of healthy controls with a CDNA probe for the GH gene. The DNA of the SRS family and those of the controls displayed the pattern expected after Bam HI digestion: $8.3 \mathrm{~kb}$ (CS-L), $6.8 \mathrm{~kb}$ (CSH2), $5.3 \mathrm{~kb}$ (CSH1), $3.8 \mathrm{~kb}$ $(\mathrm{GH}-\mathrm{N})$, and $3 \mathrm{~kb}+1.2 \mathrm{~kb}(\mathrm{GH}-\mathrm{V})$ (fig 2$)$. The sizes of all bands were normal, but both the patient's DNA and that of his father showed weaker intensities of the $5.3 \mathrm{~kb}$ band (CSH1). We conclude that the patient and his father are heterozygous for a deletion of CSH1. Digestion with HindIII confirmed this finding (not shown): the $14.8 \mathrm{~kb}$ band corresponding to $\mathrm{CSH} 1$ was weaker in the patient and his father than in controls. The other two bands, 21.3 and $25 \mathrm{~kb}$, representing $\mathrm{GH}-\mathrm{V}-\mathrm{CSH} 2$ and GH-N-CSH-L, respectively, were normal.

Taking the results of these tests together, we conclude that the deletion in the case presented here is within the $5.3 \mathrm{~kb}$ fragment of CSH1 and includes the coding region of $\mathrm{CSH} 1$ as well as the cAMP and the PMA responsive elements $(-1102$ to -1096$)$.

Alterations in the GH gene cluster have not so far been described in SRS patients. Inactivation of placental CSH and GH genes causes an abnormal biochemical phenotype, but it does not cause disease. ${ }^{17}{ }^{18} \mathrm{CSH}$ concentrations in maternal serum increase linearly until about the 30 th week and the rate of secretion is greater than that of any protein hormone. Reduced CSH secretion has been detected in different pathological conditions associated with abnormal fetal growth, including diabetes, pre-eclampsia, erythroblastosis, and intrauterine growth retardation. ${ }^{19}$ In the mother the increase of serum IGF-I during pregnancy, which is a prerequisite for adequate nutrient supply to the fetus and normal fetal growth, ${ }^{20}$ is at least in part the result of the increasing $\mathrm{CSH}$ concentrations. In pregnancies associated with fetal homozygosity for deletion of the CSH genes, maternal IGF-I concentrations decline to values normally associated with hypopituitarism. Because of this, Grumbach et $a l^{1}$

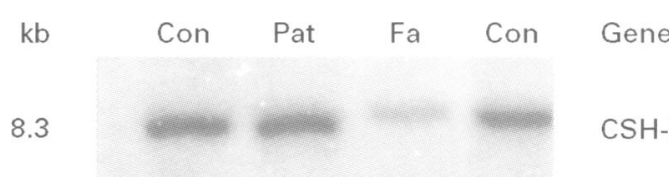
patient and his father. Band intensities were compared by eye in the patient, his father, and nine controls. The $1.2 \mathrm{~kb}$ band of $G H-V$ cannot be seen on the autoradiograph. Con =control, $P a t=$ patient, $F a=$ father.

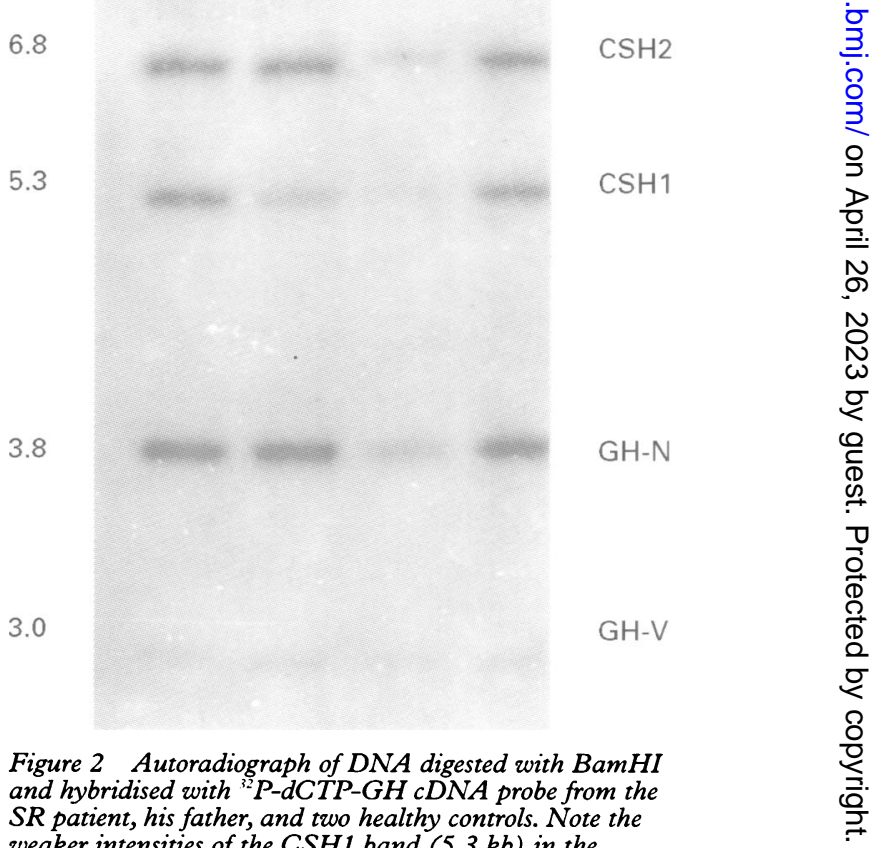


suggested a role for $\mathrm{CSH}$ in supplying of nutrients to the fetus during maternal fasting.

Although no direct effect of CSH deficiency on fetal growth has been shown so far, ${ }^{17} 18$ recent experiments indicate that $\mathrm{CSH}$ may indirectly affect fetal tissue growth. ${ }^{19} \mathrm{CSH}$ stimulates amino acid transport and uptake and IGF production and there are diabetogenic and anabolic effects of $\mathrm{CSH}$ in different fetal tissues mediated by specific $\mathrm{CSH}$ receptors. ${ }^{19}$

Additionally, it has been shown that in pathological pregnancies with intrauterine growth retardation $\mathrm{CSH}$ concentrations are reduced. ${ }^{22}$ In summary, $\mathrm{CSH}$ plays a pivotal role during pregnancy, but whether there is a relation between the heterozygous deletion in our patient and the observed intrauterine growth retardation remains unclear.

The paternally inherited heterozygous deletion of $\mathrm{CSH} 1$ we found might be an interesting finding in respect to the aetiology of intrauterine growth restriction and Silver-Russell syndrome, which to our present knowledge seems to be heterogeneous. Further analyses will show whether there are candidate genes or candidate gene clusters in the vicinity of the breakpoint $17 \mathrm{q} 25$ and whether $\mathrm{CSH} 1$ or functionally related factors are involved in the aetiology of SRS.

We are grateful to Professor J Martial, Liège, for kindly makin probe cGH800/pSPT18 available to us, and to Dr G Gilli, Olgahospital Stuttgart, for providing us with the patient's blood sample. This work was supported by the Fortüne research programme of the University of Tübingen (273/96) and a gran from Pharmacia and Upjohn, Sweden.

1 Wollmann HA, Kirchner T, Enders H, Preece MA, Ranke MB. Growth and symptoms in Silver-Russell syndrome: review on the basis of 386 patients. Eur $\mathcal{F}$ Pediat 1995;154:958-68.

2 Ramirez-Duenas ML, Medina C, Ocampo-Campos R, Rivera $H$. Severe Silver-Russell syndrome and translocation $(17 ; 20)(\mathrm{q} 25 ; \mathrm{q} 13)$. Clin Genet 1992;41:51-3.

3 Midro AT, Debek K, Samicka A, Marcinkiewicz D, Rogowska M. Second observation of Silver-Russell syndrome in a carrier of a reciprocal translocation with breakpoint at site 17q25. Clin Genet 1993;44:53-5.
4 Tamura T, Tohma T, Ohta T, et al. Ring chromosome 15 involving deletion of the insulin-like growth factor 1 recepinvolving deletion of the insulin-like growth factor 1 receptor gene in a patient with features of
syndrome. Clin Dysmorphol 1993;2:106-13.

5 Kotzot D, Schmitt S, Bernasconi F, et al. Uniparental disomy 7 in Silver-Russell syndrome and primordial disomy 7 in Silver-Russell syndrome and prim

6 Shuman C, Weksberg R, Nedelscu R, Northey A, Scherer S. Chromosome 7 uniparental disomy in Russell-Silver syndrome. Am f Hum Genet Suppl 1996;57:A284.

7 Eggermann T, Wollmann HA, Kuner R, et al. Molecular studies in 37 Silver-Russell syndrome patients: frequency and etiology of uniparental disomy. Hum Genet 1997;100: 415-19.

8 Preece MA, Price SM, Davies V, et al. Maternal uniparental disomy 7 in Silver-Russell syndrome. $\mathcal{F}$ Med Genet 1997;34: 6-9.

9 Barsh GS, Seeburg PH, Gelinas RE. The human growth hormone gene family: structure and evolution of the chrohormone gene family: structure and evolution of the

10 Parks JS, Nielsen PV, Sexton LA, Jorgensen EH. An effect of gene dosage on production of human chorionic somatomammotropin. 7 Clin Endocrinol Metab 1987;60:9947.

11 Largo RH, Wälli R, Duc G, Fanconi A, Prader A. Evaluation of perinatal growth. Helv Paediatr Acta 1989;35: 419-36.

12 Prader A, Largo RH, Molinari L, Issler C. Physical growth of Swiss children from birth to 20 years of age. Helv Paediatr Acta 1989;52(suppl):1-125.

13 Miller SA, Dykes DD, Polesky HF. A simple salting out procedure for extracting DNA from human nucleated cells. Nucleic Acids Res 1988;16:1215.

14 Polymeropoulos MH, Rath DS, Xiao H, Merril CR. A simple sequence repeat polymorphism at the human growth ple sequence repeat polymorphism at the hum

15 Koorey DJ, Bishop GA, McCaughan GW. Allele nonamplification: a source of confusion in linkage studies employing microsat

16 Martial JA, Hallewell RA, Baxter JC, Goodman HM. Human growth hormone: complementary DNA cloning and expression in bacteria. Science 1979;205:602-7.

17 Wurzel JM, Parks JS, Herd JE, Nielsen PV. A gene deletion is responsible for absence of human chorionic somatomammotropin. DNA 1982;1:251-7.

18 Simon P, Decoster C, Brocas H, Schwers J, Vassart G. Absence of human chorionic somatomammotropin during pregnancy associated with two types of gene deletion. Hum Genet 1986;74:235-8.

19 Handwerger $S$. The physiology of placental lactogen in human pregnancy. Endocr Rev 1991;12:329-36.

20 Gluckman PD. The endocrine regulation of fetal growth in late gestation: the role of insulin-like growth factors. $\mathcal{f}$ Clin Endocrinol Metab 1995;80:1047-50.

21 Grumbach MM, Kapla SL, Vinik A. hCS physiology: hormonal effects. In: Berson SA, Yalow RS, eds. Peptide hormones. New York: Elsevier/North Holland, 1973:797819.

22 Carl J, Christensen M, Mathiesen O. Human placental lactogen (hPL) model for the normal pregnancy. Placenta $1991 ; 12: 289-98$.

23 Dib C, Fauré S, Fizames C, et al. A comprehensive genetic map of the human genome based on 5,264 microsatellites. Nature 1996;380:52-138. 